\section{POS1208 EPIDEMIOLOGY AND OUTCOMES OF PATIENTS WITH RHEUMATIC DISEASES AND SARS-CoV-2 INFECTION: DATA FROM THE ARGENTINEAN SAR-COVID REGISTRY}

C. A. Isnardi ${ }^{1}$, R. Quintana ${ }^{1}$, K. Roberts ${ }^{1}$, V. V. Castro Coello ${ }^{2}$, A. A. Reyes ${ }^{2}$, Y. Tissera ${ }^{2}$, M. Cosatti ${ }^{2}$, R. Rojas Tessel ${ }^{2}$, J. Scafati ${ }^{2}$, T. Barbich ${ }^{2}$, M. S. Gálvez Elkin², G. F. Rodriguez Gil'2, S. Moyano², M. L. Werner' ${ }^{2}$, J. Rebak², J. Morbiducci' ${ }^{2}$, V. Martire ${ }^{2}$, M. S. Castaño ${ }^{2}$, C. Dieguez ${ }^{2}$, G. C. Subils², G. PonsEstel ${ }^{1}$ on behalf of SAR-COVID Registry. ${ }^{1}$ Argentina Society of Rheumatology, Research Unit, AAQ, Argentina; ${ }^{2}$ On behalf of SAR-COVID Registry, Rheumatology, Ciudad Autónoma de Buenos Aires, Argentina

Background: In the last time, many papers about SARS-CoV-2 have been published in the world. However, data from latinamerican patients is still scarce. In order to assess the impact of SARS-CoV-2 infection in patients with rheumatic diseases in our country and contribute to the global knowledge about the effect of immunosuppressive therapies in this group, the Argentine Society of Rheumatology has developed the National Registry of Patients with Rheumatic Diseases and COVID-19 (SAR-COVID).

Objectives: The aim of this study was to evaluate clinical characteristics and outcomes of SARS-CoV-2 infection in patients with rheumatic diseases, treated or not with immunomodulators and/or immunosuppressants.

Methods: SAR-COVID is a national, multicenter, prospective and observational registry, in which patients, $\geq 18$ years of age, with a diagnosis of a rheumatic disease who had SARS-CoV-2 infection (PCR or positive serology) are consecutively included between August 13, 2020 and January 17, 2021. Sociodemographic data, comorbidities, underlying rheumatic disease and treatment, clinical characteristics, complications, laboratory and treatment of the SARS-CoV-2 infection were recorded. Hospitalization, mechanical ventilation requirements and death were assessed to evaluate COVID-19 outcome. Statistical analysis: Descriptive analysis. Chi ${ }^{2}$ or Fischer test and T test or Mann-Whitney $U$ test or ANOVA, as appropriate. Multiple logistic regression.

Results: A total of 525 patients were included, $80.4 \%$ were female, with a median age of 52 years (IQR 40-62). Comorbidities were reported in half of them $(53.3 \%)$. The most frequent rheumatological diseases were rheumatoid arthritis $(40.4 \%)$ and systemic lupus erythematosus (14.9\%). At the time of the infection, most of them were in remission or in minimal/low disease activity $(68.2 \%)$ and $72.9 \%$ were receiving immunosuppressive or immunomodulatory treatment. Symptoms were present in $96 \%$ of the patients, the most frequent being fever $(56.2 \%)$, cough $(46.7 \%)$ and headache $(39.2 \%)$. During infection, $35.1 \%$ received some pharmacological treatment, dexamethasone $(20 \%)$ the most frequently used. One third $(35.1 \%)$ of the patients were hospitalized, $11.6 \%$ were admitted to the ICU, $10.1 \%$ needed mechanical ventilation and $6.9 \%$ died due to COVID-19. Complications were reported in $12.4 \%$, being acute respiratory distress syndrome the most prevalent $(8.8 \%)$.

Patients over 65 years of age were more frequently hospitalized, admitted to the ICU, needed mechanical ventilation and died due to COVID-19 (50\% vs $31.4 \%$, $22 \%$ vs $9 \%, 16.3 \%$ vs $5.2 \%, 14 \%$ vs $5 \%$, respectively; $p<0.001$ in all cases). Similar results were seen in patients with vasculitis $(57.7 \%$ vs $33.9 \%, 46.2$ vs $9.8 \%, 34.6 \%$ vs $6 \% ; 30.8 \%$ vs $5.6 \%$, respectively; $p<0.001$ in all cases) and those with moderate/high disease activity $(55.7 \%$ vs $26.5 \%, 21.3$ vs $7.8 \%, 17.2 \%$ vs $4.2 \% ; 17.2 \%$ vs $4.2 \%$, respectively; $p<0.001$ in all cases). Patients with APS were more frequently admitted to the ICU $(29.4 \%$ vs $11 \%, p=0.037)$. The presence of comorbidities was associated with higher hospitalization $(46 \%$ vs $22.6 \%, p<0.001)$, admission to the ICU $(17.2 \%$ vs $5.9 \%, p<0.001)$ and mechanical ventilation $(10.2 \%$ vs $4.6 \%, p=0.028)$. Immunosuppressive treatment was not associated with worse outcomes.

Conclusion: In this cohort of patients with a wide distribution of rheumatic diseases, we have found clinical characteristics similar to those reported by other international cohorts. Compared with national data, the mortality reported in these patients is higher. However, it should be noted that these are early data collected during isolation and that there may be an underreporting of asymptomatic patients or with mild symptoms who do not attend the rheumatologist.

Older patients, those with comorbidities, with vasculitis and with higher disease activity showed poor COVID-19 outcomes.

Disclosure of Interests: Carolina Ayelen Isnardi Speakers bureau: Janssen, BMS, Grant/research support from: Unrestricted grants: Pfizer, Abbvie, Elea Phoenix. None of them have access to patient data., Rosana Quintana Grant/ research support from: Unrestricted grants: Pfizer, Abbvie, Elea Phoenix. None of them have access to patient data., Karen Roberts Grant/research support from: Unrestricted grants: Pfizer, Abbvie, Elea Phoenix. None of them have access to patient data., Vanessa Viviana Castro Coello Grant/research support from: Unrestricted grants: Pfizer, Abbvie, Elea Phoenix. None of them have access to patient data., Alvaro Andres Reyes Grant/research support from: Unrestricted grants: Pfizer, Abbvie, Elea Phoenix. None of them have access to patient data., Yohana Tissera Grant/research support from: Unrestricted grants: Pfizer, Abbvie, Elea Phoenix. None of them have access to patient data., Micaela Cosatti Grant/ research support from: Unrestricted grants: Pfizer, Abbvie, Elea Phoenix. None of them have access to patient data., Romina Rojas Tessel Grant/research support from: Unrestricted grants: Pfizer, Abbvie, Elea Phoenix. None of them have access to patient data., Julia Scafati Grant/research support from: Unrestricted grants: Pfizer, Abbvie, Elea Phoenix. None of them have access to patient data. Tatiana Barbich Grant/research support from: Unrestricted grants: Pfizer, Abbvie, Elea Phoenix. None of them have access to patient data., María Soledad Gálvez Elkin Grant/research support from: Unrestricted grants: Pfizer, Abbvie, Elea Phoenix. None of them have access to patient data., Gustavo Fabian Rodriguez Gil Grant/research support from: Unrestricted grants: Pfizer, Abbvie, Elea Phoenix. None of them have access to patient data., Sebastian Moyano Grant/ research support from: Unrestricted grants: Pfizer, Abbvie, Elea Phoenix. None of them have access to patient data., Marina Laura Werner Grant/research support from: Unrestricted grants: Pfizer, Abbvie, Elea Phoenix. None of them have access to patient data., Jonathan Rebak Grant/research support from: Unrestricted grants: Pfizer, Abbvie, Elea Phoenix. None of them have access to patient data., Julieta Morbiducci Grant/research support from: Unrestricted grants: Pfizer, Abbvie, Elea Phoenix. None of them have access to patient data., Victoria Martire Grant/research support from: Unrestricted grants: Pfizer, Abbvie, Elea Phoenix. None of them have access to patient data., María Sol Castaño Grant/research support from: Unrestricted grants: Pfizer, Abbvie, Elea Phoenix. None of them have access to patient data., Carolina Dieguez Grant/ research support from: Unrestricted grants: Pfizer, Abbvie, Elea Phoenix. None of them have access to patient data., Gisela Constanza Subils Grant/research support from: Unrestricted grants: Pfizer, Abbvie, Elea Phoenix. None of them have access to patient data., Guillermo Pons-Estel Grant/research support from: Unrestricted grants: Pfizer, Abbvie, Elea Phoenix. None of them have access to patient data.

DOI: 10.1136/annrheumdis-2021-eular.2250

\section{POS1209 \\ SUCCESSFUL TREATMENT OF SEVERE COVID- 19 PNEUMONIA AND CYTOKINE RELEASE WITH SIMULTANEOUS TOCILIZUMAB AND ANAKINRA WITH ONE-MONTH FOLLOW-UP}

H. Haibel ${ }^{1}$, J. L. Vahldiek ${ }^{2}$, S. Angermair ${ }^{3}$, M. Schumann ${ }^{4}$, B. Siegmund ${ }^{5}$, D. Poddubnyy ${ }^{1}$, T. Schneider $6 .{ }^{1}$ Charité - Universitätsmedizin Berlin, Campus Benjamin Franklin, Rheumatology, Berlin, Germany; ${ }^{2}$ Charité Universitätsmedizin Berlin, Campus Benjamin Franklin, Radiology, Berlin, Germany; ${ }^{3}$ Charité - Universitätsmedizin Berlin, Campus Benjamin Franklin, Anestesiology and Surgical Intensive Care, Berlin, Germany; ${ }^{4}$ Charité Universitätsmedizin Berlin, Campus Benjamin Franklin, Gastroenterology, Berlin, Germany: ${ }^{5}$ Charité - Universitätsmedizin Berlin, Campus Benjamin Franklin, Gastroenterology, Infectiology and Rheumatology, Berlin, Germany; ${ }^{6}$ Charité - Universitätsmedizin Berlin, Campus Benjamin Franklin, Infectiology, Berlin, Germany

Background: Severe and life threating COVID-19 pneumonia is often characterized by local and systemic immune-mediated hyperinflammation At the early disease stage activated monocytes are migrating to the lung and cause the typical opac infiltrates, which lead to an reduction of oxygen uptake. These pathophysiological observations and the fact that corticosteroids are so far the only drug, which has shown significant improvement, was the rationale use this combination anti-inflammatory drugs in severe Covid-19 disease. Interleukin (IL)- 6 and IL-1 blockade alone, respectively showed contradictory results in severe COVID-19 pneumonia that might be related to the differences is patient populations (early vs. late stage) and to the fact that blockade of just one cytokine might be not sufficient against the cytokine storm.

Objectives: Here we report results of an open-label treatment with a combination of an IL-6 receptor blocker tocilizumab and an IL-1 receptor antagonist anakinra in patients with early (up to 10 days since symptom onset) severe COVID-19 pneumonia with evidence of cytokine release.

Methods: Adult patients with, according to World Health Organisation criteria, severe to critical COVID-19 infection associated pneumonia and cytokine release, requiring oxygen supplementation and evidence of rapid deterioration and decrease of oxygen saturation to $\leq 95 \%$ hospitalized between May 2020 and December 2020 were treated with tocilizumab $8 \mathrm{mg} / \mathrm{kg}$ up to $800 \mathrm{mg}$ intravenously and anakinra 100 to $300 \mathrm{mg}$ for 3 to 5 days, starting at the same day. We excluded patients with a symptom duration of $>10$ days, patients with evidence of bacterial infection, indicated by an elevated procalcitonin serum level, patients with severe pre-existing lung disease such as severe COPD or heart failure of $>\mathrm{II}$ according to the NYHA classification and patients $>80$ years. Laboratory parameters and chest CT were performed on initial presentation and one month after treatment. A semi-quantitative CT score was calculated based on the extent of lobar pneumonia involvement $(0: 0 \% ; 1,<5 \% ; 2: 5-25 \% ; 3: 26-50 \% ; 4: 51-75 \%$; 5 , > 75\%; range 0-5; global score 0-25) for each time point.

Results: 15 patients with severe to critical COVID-19 pneumonia and signs of cytokine release, mean age 55 (range 31-79) years, all male, with a mean 